\title{
Relationship Between the Inoculum Density of Verticillium dahliae and the Progress of Verticillium Wilt of Olive
}

\author{
F. J. López-Escudero and M. A. Blanco-López, Departamento de Agronomía, ETSIAM, Universidad de Córdoba, \\ Apdo. 3048, 14080, Córdoba, Spain
}

\begin{abstract}
López-Escudero, F. J., and Blanco-López, M. A. 2007. Relationship between the inoculum density of Verticillium dahliae and the progress of Verticillium wilt of olive. Plant Dis. 91:1372-1378.
\end{abstract}

An experiment was conducted in microplots which were artificially infested with a defoliating isolate of Verticillium dahliae using seven different treatments of inoculum densities ranging from 0 to 10 microsclerotia per gram of soil (ppg). The experiment was conducted in Andalucía (southern Spain), and the susceptible Spanish olive cv. Picual was used to determine the relationship between pathogen inoculum density and the progress of Verticillium wilt of olive (VWO). The inoculum, produced on a sodium pectate cellophane medium, was found to efficiently infect olive trees. Symptoms first appeared 30 weeks after the trees were transplanted into infested soil. Periods of increasing disease incidence in the following seasons and years were mainly during spring and autumn, particularly in the second year after planting. Olive trees exhibited a high susceptibility to the defoliating pathotype of the pathogen, even at very low inoculum levels; in fact, diseased plants were encountered throughout the experiment regardless of the inoculum density treatment. Inoculum densities greater than $3 \mathrm{ppg}$ in the soil resulted in final disease incidence greater than $50 \%$ for the trees after 2.5 years. Therefore, these inoculum densities must be considered very high for olive trees. There were no differences in final disease incidence, mean symptom severity, or area under the disease progress curve between plots infested with 10 or $3.33 \mathrm{ppg}$, whereas other treatments exhibited lower values for each of these disease parameters. The temporal variations of disease incidence and severity were highly correlated for the higher inoculum density treatments, with $r^{2}$ values ranging from 0.92 to 0.84 for disease incidence and from 0.93 to 0.88 for severity. However, $r^{2}$ was slightly lower for the treatments involving lower inoculum densities of the pathogen in microplots. The slopes of the linear regression curves were statistically different for nearly all the inoculum density treatments. Positive correlation was found between the initial inoculum density and final disease incidence values after the study period that was accurately explained by mathematical models. The results suggest that susceptible olive cultivars should not be planted in soils infested with virulent defoliating pathotypes of $V$. dahliae. Results also clarify that inoculum density levels obtained from field soil analyses can be used for establishing a risk prediction system with a view to controlling VWO in olive tree plantations.

Verticillium wilt of olive (VWO), caused by Verticillium dahliae, is a major disease affecting olive orchards in Spain $(17,18,24)$ and throughout the Mediterranean area, where this tree crop typically is grown (14). Planting resistant cultivars is the most effective tool for reducing spread of the disease $(14,18)$. However, the most important Spanish cultivars, Picual, Hojiblanca, Cornicabra, and Arbequina, are susceptible or extremely susceptible to defoliating and nondefoliating $V$. dahliae isolates (18). Also, the resistance to VWO under field conditions is strongly influ-

Corresponding author: M. A. Blanco-Lopez

E-mail: mblanco@uco.es

Accepted for publication 9 April 2007.

doi:10.1094/PDIS-91-11-1372

(C) 2007 The American Phytopathological Society enced by a number of factors, including the environment, inoculum density (ID), pathogen virulence, and management practices (14). These factors vary widely in the Guadalquivir Valley (southern Spain) as a result of highly variable soil types, temperature, and irrigation regimes for table olive and olive oil production. In addition, a number of major herbaceous hosts of the pathogen, such as cotton, potato, sugar beet, sunflower, and vegetables, typically are grown close to olive trees. This has resulted in soils in many areas of the valley being infested by the pathogen at IDs ranging from 2.0 to 10.0 propagules per gram of soil (ppg) of nondefoliating isolates in the upper and central valley, and from 2.0 to $132.0 \mathrm{ppg}$ of mixtures of nondefoliating and defoliating isolates in the lower valley $(3,4)$. In the last 20 years, a large portion of new olive plantations has been established in these areas, which encompass a wide range of soils into which defoliating isolates of $V$. dahliae have already spread $(4,17)$. Available information from field experiments and surveys has revealed soil to contain variable Verticillium ID levels $(17,19)$. Also, olive has been found to be highly susceptible to $V$. dahliae infections in the field; in fact, in some fields and plots exhibiting a varying incidence of VWO, the pathogen population in soil is very low or even undetectable (17).

Various herbaceous hosts of $V$. dahliae have been shown to exhibit a direct relationship between the pathogen ID in soil at sowing and progression of the disease $(10,21-23,30)$. In other cases, however, no such relationship could be established, or the results were inconsistent and strongly depended on the particular location (soil type and environmental conditions), cultivar susceptibility, or pathogen race or pathotype $(1,4,12,13,16)$.

There is little available information about the relationship between $V$. dahliae ID at or before planting and disease incidence (DI) and progression in tree crops such as olive. Available data have been obtained indirectly from some studies, where the variation of ID in soil and wilt disease development were evaluated in assessing the effectiveness of control measures to reduce the presence of $V$. dahliae in soil during field experiments $(17,28)$. However, any conclusions on the relationship drawn from these studies may not be reliable because the specific pathogen ID in the soil at the time of planting was unknown and the natural ability of olive trees to recover from the disease may have interfered with the assessment of disease progression.

One other important point is that the epidemiological implications of the spread of defoliating pathotypes of the pathogen throughout olive-growing areas are unknown. This is specially important in Andalucía (southern Spain), where more than 1.3 million ha of olive orchards have been planted and the disease has become a serious problem. Therefore, the aim of this study was to determine the relationship between the ID of the defoliating pathotype of $V$. dahliae in soil and the progress of VWO in the most important Spanish olive cv. Picual. The results should clarify the significance of the ID values provided 
by field soil analyses and can be used to establish a risk prediction system for controlling VWO.

\section{MATERIALS AND METHODS}

Artificial production of microsclerotia. The experiment was conducted under semicontrolled conditions, using microplots that were infested by artificially produced microsclerotia of $V$. dahliae. A well-characterized isolate of $V$. dahliae, V117, from the collection of the Plant Pathology laboratory of the Agronomy Department, University of Córdoba, was used as inoculum. This inoculum represents a highly virulent defoliating isolate of the pathogen (5). The isolate was maintained on potato dextrose agar (PDA) slants at $4^{\circ} \mathrm{C}$. Plates of a 6-day-old singlespore culture incubated on PDA at $24^{\circ} \mathrm{C}$ in the dark were used to prepare a conidial suspension by adding sterile distilled water to the plates and gently rubbing the surface of the colony with a sterile, bent glass rod. The resulting conidial suspension was filtered through a double layer of sterile cheesecloth and adjusted to obtain a concentration of $10^{7}$ conidia/ml. Microsclerotia of the pathogen were produced by plating the conidial suspension at 0.5 $\mathrm{ml} /$ plate onto PDA covered with a sterilized permeable cellophane disc $600 \mu \mathrm{m}$ in thickness (UCB Film, La Cellophane Española S. A.). After 8 to 10 days of incubation at $22^{\circ} \mathrm{C}$ in the dark, the cellophane sheet was removed and microsclerotia were collected from it in sterile water with the aid of a paintbrush. In order to remove mycelium debris and conidia, the microsclerotial suspension was homogenized in a blender at high speed, and then filtered in tandem through $150-$ and $35-\mu \mathrm{m}$ sieves. The residue retained on the $35-\mu \mathrm{m}$ sieve was recovered in a $100-\mathrm{ml}$ flask containing sterilized water. The suspension was allowed to stand in a separating funnel for $1 \mathrm{~h}$, after which the top layer was removed and discarded. The slurry containing the microsclerotia then was spread uniformly onto empty glass petri dishes and placed in a drying chamber at $28^{\circ} \mathrm{C}$ for 2 days. Finally, the isolated dried microsclerotia were collected by scraping them off the petri dishes with a scalpel and mixing with sterile talc $(1: 10 \mathrm{vol} / \mathrm{vol})$ for storage at $4^{\circ} \mathrm{C}$ for 4 weeks. The viability over time and infective capability of microsclerotia were confirmed previously under controlled conditions in cotton (20).

Microplot establishment and experimental design. The experiment was conducted in a plot located in Campus de Rabanales (Universidad de Córdoba, Spain). In 2000 , a line of microplots was constructed that consisted of 28 concrete containers, each $1 \mathrm{~m}^{2}$ by $50 \mathrm{~cm}$ deep and open at the bottom. The microplot row was protected from rain and excessive sun by a galvanized steel cover. A randomized complete block design was used for seven ID levels of the pathogen $(0,0.04,0.12,0.37$, $1.11,3.33$, and $10 \mathrm{ppg}$ ), designated $\mathrm{T0}$ to T6, and applied to each of four replications (microplots).

Soil infestation and transplanting. In November 2000 , about $14,000 \mathrm{~kg}$ of a natural loam soil was mixed to assure uniformity. The soil was established to be free of $V$. dahliae by using the wet sieving technique (15) with plates of a modified sodium polypectate agar (MSPA) medium (7). Inoculum packets for each of the seven ID treatments were prepared by weighing appropriate amounts of the microsclerotia and talc mixture. Pre-inoculum bags then were prepared by mixing the inoculum packets with $1 \mathrm{~kg}$ of autoclaved sterile sandy soil in a concrete mixer. Each preinoculum bag was mixed with $300 \mathrm{~kg}$ of the natural loam soil by a concrete mixer. Each microplot was filled first with $100 \mathrm{~kg}$ of inoculum-free soil, spread by hand into an even layer; then, $300 \mathrm{~kg}$ of soil infested with the appropriate ID was poured into each microplot for a second layer. Finally, the microplots were filled up with an additional $100 \mathrm{~kg}$ of inoculum-free soil for the top layer. Nine-month-old soft olive cuttings of the susceptible cv. Picual $(17,18)$ were transplanted with the aid of a manual transplanter to each microplot (nine plants per microplot). Root systems were placed at the same depth in the soil profile as the inoculum layer. Plants were irrigated by an automated controlled drip system with an average irrigation rate of 15 liters per microplot per week during the autumn and winter and 40 liters during the spring and the summer.

V. dahliae inoculum density in the soil. The pathogen population for each treatment was determined in May of the first (2001), second (2002), and third (2003) year after planting in order to monitor changes in ID over time. One $100-\mathrm{g}$ soil sample was taken from a depth of 25 to 30 $\mathrm{cm}$ in each microplot by using a cylindrical auger. Samples of the four replications of each treatment were mixed, bulked, and crumbled. Soil samples then were air dried under ambient conditions for 3 weeks. Each sample then was passed through a $0.8-\mathrm{mm}$ sieve to remove organic debris and large particles, mixed by hand, and air dried for an additional week. The $V$. dahliae ID was estimated by the wet sieving technique (15). An amount of $25 \mathrm{~g}$ of each sample was suspended in $100 \mathrm{ml}$ of distilled water, shaken at $270 \mathrm{rpm}$ for $1 \mathrm{~h}$, and filtered through $150-$ and $35-\mu \mathrm{m}$ sieves. The residue retained on the $35-\mu \mathrm{m}$ sieve was recovered in $100 \mathrm{ml}$ of distilled water. Finally, $1 \mathrm{ml}$ of the suspension from each treatment was plated onto MSPA plates. After 14 days of incubation at 22 to $24^{\circ} \mathrm{C}$ in the dark, soil residues were removed with tap water and colonies of $V$. dahliae counted under a stereoscope. The ID in each soil sample was estimated by the number of colonies of $V$. dahliae and ex- pressed as propagules or microsclerotia per gram of air-dried soil.

Disease progress. Trees were surveyed each week for symptom development during a period of 30 months. Disease severity was estimated by using a 0-to-4 rating scale according to the percentage of affected plant tissue exhibiting any chlorosis, necrosis, or defoliation, where $0=$ no symptoms; $1=1$ to $33 \%, 2=34$ to $66 \%$, and $3=67$ to $99 \%$ affected tissue; and $4=$ dead plant. The percentage of diseased trees and of dead plants relative to the total number subjected to each treatment then were determined. At the end of surveys (July 2003), the area under the disease progress curve estimated as the percentage relative to the maximum possible value in the studied period (AUDPCP) was determined, using the formula based on Campbell and Madden (8): AUDPCP $=\left[t / 2 \times\left(s_{2}\right.\right.$ $\left.\left.+2 \times s_{3}+\ldots+2 \times s_{i-1}+s_{i}\right) / 4 \times n\right] \times 100$, where $t=$ interval in days between observations, $s_{i}=$ final mean severity of the $i$ th observation, $4=$ maximum value for severity, and $n=$ total number of observations. The disease-related parameter values for plants treated with different IDs were used to construct progress curves for disease incidence of affected plants, mean severity of symptoms, and percentage of dead plants over time for the entire studied period.

Linear trends in the increase of DI over time for each ID treatment were determined through standard least-square regression analyses on nontransformed data (straight-line and second-order polynomial models). Logistic, log-logistic, and monomolecular mathematical models also were evaluated using regression analysis. Model fit was evaluated via the coefficient of determination $\left(r^{2}\right)$, the standard error and significance of the estimated parameters, the mean error square, and the residual pattern $(8,9)$. Slopes (rate of disease increase) of the best-fitting regression lines for each ID treatment also were compared. In addition, mean mortality time (mean time from initial symptom observation to plant death) and the time from transplanting of trees to the infested soil to when symptoms initially were observed were determined for all ID treatments.

Infection of the plants was confirmed by pathogen reisolation from affected twigs during the observation period, as well as from all the dead plants. For pathogen isolation, pieces of affected tissues were washed in running tap water, bark was removed, and woody tissue surfaces disinfested in $0.5 \%$ sodium hypochlorite for 1 min. Wood chips were placed onto PDA and plates incubated at $24^{\circ} \mathrm{C}$ in the dark for 5 to 6 days.

Relationship between final disease and inoculum density. The final numbers of plants exhibiting some symptom after the 30 months of observation were regressed on the pathogen ID initially added 
to the soil of microplots. The following mathematical models were tested by linear regression analyses: (i) nontransformed data (DI versus ID); (ii) semilogarithmic (monomolecular), or multiple infection transformation $\left(\ln [1-\mathrm{DI}]^{-1}\right.$ versus ID) $(11,12)$; (iii) Baker's transformation $\left(\log \left[\ln (1-\mathrm{DI})^{-1}\right]\right.$ versus $\log$ ID) $(2)$; (iv)
Table 1. Inoculum density over time for the defoliating pathotype of Verticillium dahliae in an artificially infested soil in microplots subjected to different treatments ${ }^{\mathrm{y}}$

\begin{tabular}{lccccc}
\hline & \multicolumn{4}{c}{ Inoculum density of $\boldsymbol{V}$. dahliae $(\mathbf{p p g})^{\mathbf{z}}$} \\
\cline { 2 - 5 } & Infested & & \multicolumn{3}{c}{ Recovered } \\
\cline { 2 - 4 } \cline { 5 - 6 } Treatment & November 2000 & & May 2001 & May 2002 & May 2003 \\
\hline T6 & 10.00 & & 3.10 & 3.73 & 7.20 \\
T5 & 3.33 & & 1.60 & 2.60 & 2.40 \\
T4 & 1.11 & & 0.00 & 0.80 & 0.40 \\
T3 & 0.37 & & 0.20 & 0.26 & 0.40 \\
T2 & 0.12 & & 0.00 & 0.00 & 1.20 \\
T1 & 0.04 & & 0.00 & 0.00 & 0.00 \\
T0 & 0.00 & & 0.00 & 0.00 & 0.00 \\
\hline
\end{tabular}

${ }^{y}$ Inoculum density was assessed by wet sieving with Modified Polypectate Sodium Agar media with 20 replications (plates) per analysis.

${ }^{\mathrm{z}}$ Propagules or microsclerotia per gram of soil $=$ ppg.

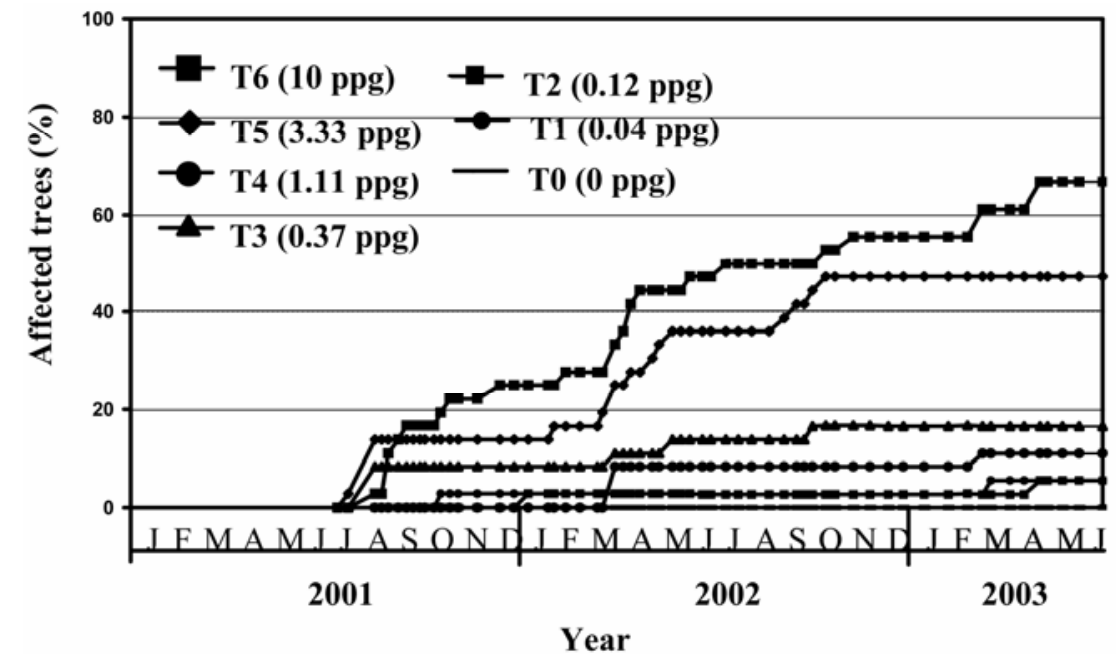

Fig. 1. Disease incidence over time of Verticillium wilt of olive in microplots artificially infested with different inoculum densities of Verticillium dahliae. $\mathrm{T} 6$ to $\mathrm{T} 0=$ inoculum density treatments; ppg = propagules (microsclerotia) per gram of soil.

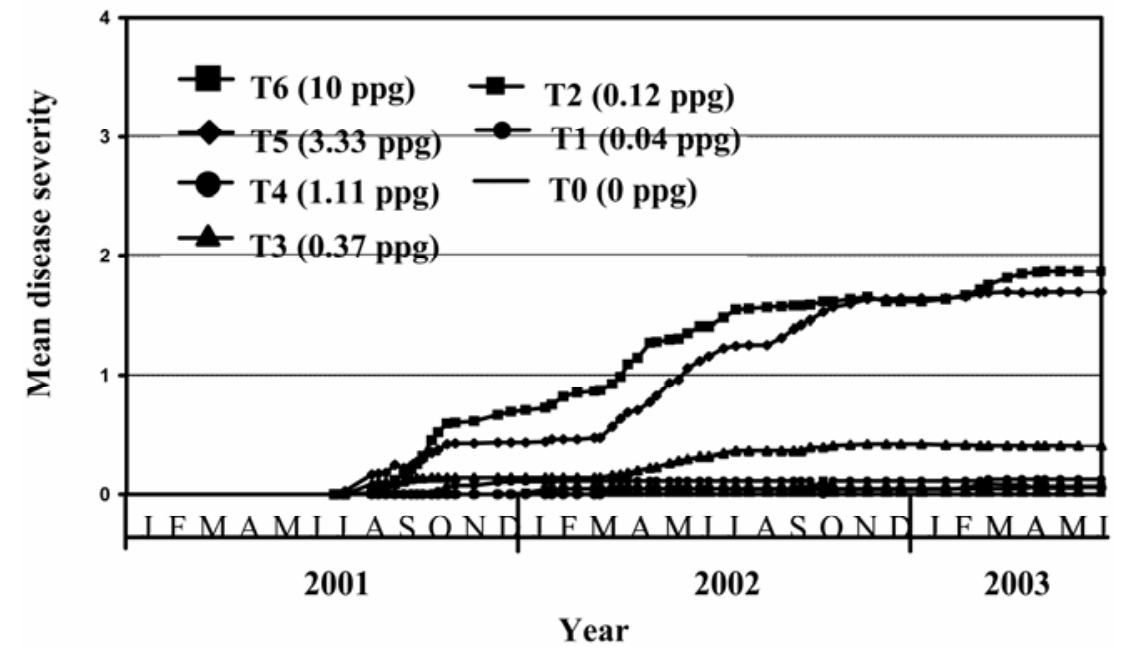

Fig. 2. Mean severity of symptoms of Verticillium wilt over time in olive trees in microplots artificially infested with different inoculum densities of Verticillium dahliae. Disease severity was estimated on a 0to- 4 rating scale according to the percentage of plant tissue affected by any of the following symptoms: chlorosis, necrosis, or defoliation $(0=$ no symptoms; $1=1$ to $33 \%, 2=34$ to $66 \%$, and $3=67$ to $99 \%$ affected tissue; and $4=$ dead plant). $\mathrm{T} 6$ to $\mathrm{T} 0=$ inoculum density treatments; ppg = propagules (microsclerotia) per gram of soil. direct $\log$-log transformation (log DI versus log ID) (1); and (v) logit transformation $(\ln [\mathrm{DI} /(1-\mathrm{DI})]$ versus $\log \mathrm{ID})(29)$. Similar linear regression analyses also were used for the final AUDPCP values. Goodness of fit was assessed from the coefficient of determination $\left(r^{2}\right)$, the significance of the relationship, and the residual pattern. All statistical analyses were performed by using Statistix 8.0 for Windows (Analytical Software, Tallahassee, FL).

Soil and air temperature and seasonal increments of disease incidence. Air and soil (at a depth of $25 \mathrm{~cm}$ in the microplots) temperatures were measured and recorded at 5-min intervals by using a data logger (DL2e; Delta-T Devices Ltd, Cambridge, UK). Probes were set into each of four microplots for monitoring soil temperatures; two of these probes recorded both air and soil temperatures. The daily average air and soil temperatures in the microplot experiment were plotted together with the monthly values of the number of diseased trees affected by VWO.

\section{RESULTS}

Inoculum density of $\boldsymbol{V}$. dahliae in soil. Soil analyses of ID at a depth of $30 \mathrm{~cm}$ revealed that microsclerotia of the pathogen were present in this zone and retained a high viability during the study period (Table 1). The efficacy of the wet-sieving technique to estimate the number of propagules of $V$. dahliae varied. In May of the first year, 21 weeks after soil infestation, the proportion of inoculum detected in the soil was $30,48,18$, and $50 \%$ of the inoculum initially added in treatments T6, $\mathrm{T} 5$, T4, and $\mathrm{T} 3$, respectively (Table 1 ). Pathogen was not detected in the soils at the lowest ID treatments. In May of the second year (2002), 73 weeks after soil infestation, the ID to treatments T4 and T5 were 72 and $78 \%$ of initial infestation levels, respectively; by contrast, treatments T3 and T6 exhibited a very small increase in ID. The final values recorded in May of the third year after plot establishment revealed a significant increase in ID only in the microplots that were infested at the highest ID levels (T6, $10 \mathrm{ppg}$ ), in which a 7.2-ppg concentration of the pathogen was detected. With the lowest ID (T1), the 0.04 ppg initially added to microplots remained undetectable through the three measurement times.

Disease progress. The onset of symptom development was observed 30 weeks (July 2001) after transplanting in November 2000, in plants grown on the soils containing the highest ID levels (T5 and T6; Figs. 1 and 2; Table 2). The affected plants exhibited typical symptoms of the disease: wilting and dieback, defoliation, or both. The initial symptoms were partial wilting of the lower branches followed by sudden generalized defoliation of green leaves. In some cases, the first symptom was partial 
defoliation of green leaves on the higher branches. At the end of summer in 2001 and during 2002, affected plants exhibited wilt, chlorosis, and rolling of leaves without defoliation of green leaves. These plants became completely wilted, and necrotic leaves remained attached to branches. During the autumn, defoliation of green leaves throughout the plants was commonly observed. Tissues from stems from all plants exhibiting foliar symptoms produced $V$. dahliae upon culturing on PDA after 5 to 6 days of incubation, confirming the infection.

Diseased plants were detected with all ID treatments during the experiment (Fig. 1 ); however, the final values of diseaserelated parameters varied among treatments (Figs. 1 to 3; Table 2). Results indicated a significant break point between treatments $\mathrm{T} 1$ and $\mathrm{T} 4$ and treatments $\mathrm{T} 5$ and T6. Disease incidence in the microplots infested with $10 \mathrm{ppg}$ (T6) and 3.33 ppg (T5) increased continuously with time throughout the 3 years (Fig. 1). At the end of the experiment, these two treatments were similar for final values of DI, severity of symptoms, and percentage of dead plants, but differed from the other treatments, $\mathrm{T} 1$ to $\mathrm{T} 4$, with ID values ranging from 0.04 to 1.11 (Figs. 1 to 3, Table 2). The final mean DI for treatments T6 and T5, 134 weeks after planting in the infested soil, was $55.5 \%$ of affected trees; meanwhile, the mean for the other treatments was only $9.7 \%$ (Table 2). Moreover, same mean values for treatments T6 and T5 for the final mean severity and AUDPCP values were 1.77 and $34.4 \%$, respectively; these parameters were less than 0.4 and $15 \%$ for treatments $\mathrm{T} 1$ to $\mathrm{T} 4$ (Table 2).

Least-squares regression analysis of untransformed data on frequency of plants affected by wilt and symptom severity development over time are summarized in Table 3. The straight-line model was chosen for this purpose because it was the simplest and easiest to use, and also be- cause the second-order polynomial model resulted in no significant improvement in goodness of fit. The percent temporal variation in the two disease parameters explained by this model was higher for the ID treatments consisting of 10.0, 3.33, and $0.37 \mathrm{ppg}$; the resulting $r^{2}$ values ranged from 0.92 to 0.84 for DI and from 0.93 to 0.88 for symptom severity (Table 3 ). However, $r^{2}$ was slightly smaller for the treatments with the lower pathogen ID in the microplot soil. A comparison of the slopes of the regression lines for DI development over time for the different ID treatments showed the rate of disease increase to be significantly different for all treatments except T3 and T4 (Table 4). Also, the rate of disease increase was proportional to the ID in the soil.

The final percentage of dead plants also was strongly influenced by the soil ID, with up to $41.6 \%$ of the plants dying when grown in the microplots infested with 10.00 and $3.33 \mathrm{ppg}$, and only 0 to $8.3 \%$ dying in the remaining treatments (Table
2). However, the proportion of plants that died among those showing symptoms was $50 \%$ greater with treatments T6, T3, and $\mathrm{T} 1$, and up to $88.2 \%$ in the trees subjected to T5. The mean mortality time ranged from 10 to 17 weeks after observation of symptom development.

For the plants that exhibited symptoms throughout the study period, the period preceding symptom development in infected plants ranged from 30 to 125 weeks (Table 2). Statistical analyses revealed no significant differences between treatments T6 and T5 regarding this period preceding symptoms. Other treatments were not analyzed due to the low number of affected plants.

Relationship between final disease and inoculum density. The mathematical models of Baker, direct log-log, and logit transformations revealed significant linear correlation between the IDs and frequencies of the plants that exhibited wilt symptoms. The direct log-log transformation was the best model fit, resulting in the

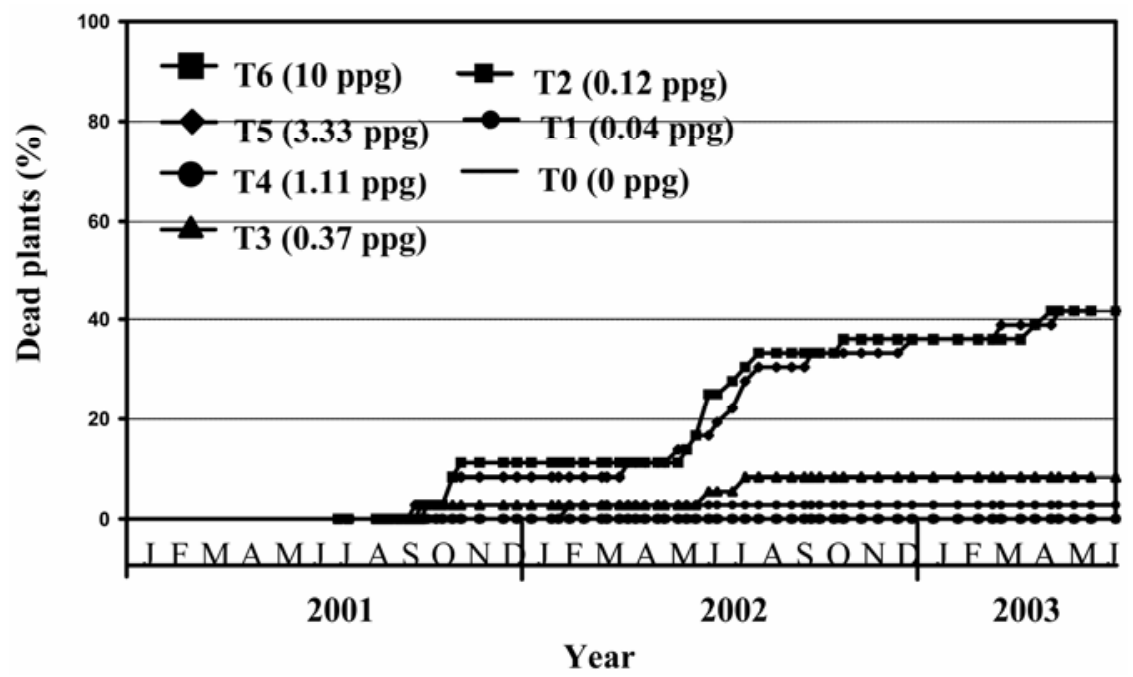

Fig. 3. Cumulative numbers of dead olive trees over time in microplots artificially infested with different inoculum densities of Verticillium dahliae. $\mathrm{T} 6$ to $\mathrm{T} 0=$ inoculum density treatments; ppg = propagules (microsclerotia) per gram of soil.

Table 2. Effect of inoculum density (ID) of Verticillium dahliae on the final estimated values of the disease parameters for olive trees in artificially infested microplots $^{\mathrm{u}}$

\begin{tabular}{|c|c|c|c|c|c|c|c|c|c|}
\hline \multirow[b]{2}{*}{ Treat, ID (ppg) ${ }^{\mathrm{w}}$} & \multicolumn{2}{|c|}{$\begin{array}{l}\text { First symptoms } \\
\text { (weeks) }\end{array}$} & \multirow[b]{2}{*}{ Final DI (\%) } & \multirow[b]{2}{*}{ Final MS } & \multirow[b]{2}{*}{ Dead plants (\%) } & \multirow[b]{2}{*}{$\operatorname{AUDPCP}(\%)^{\mathrm{y}}$} & \multicolumn{2}{|c|}{ Affected plants ${ }^{v}$} & \multirow[b]{2}{*}{ MM (weeks) } \\
\hline & Range & Mean & & & & & Final MS & Dead plants (\%) & \\
\hline T6, 10.00 & $34-121$ & 66 & $63.8 \mathrm{a}$ & $1.86 \mathrm{a}$ & $41.6 \mathrm{a}$ & $36.54 \mathrm{a}$ & 2.92 & 65.2 & 14 \\
\hline $\mathrm{T} 5,3.33$ & 30-95 & 63 & $47.2 \mathrm{a}$ & $1.69 \mathrm{a}$ & $41.6 \mathrm{a}$ & $32.43 \mathrm{a}$ & 3.58 & 88.2 & 17 \\
\hline $\mathrm{T} 4,1.11$ & $67-117$ & 79 & $11.1 \mathrm{~b}$ & $0.05 \mathrm{~b}$ & $0 \mathrm{~b}$ & $8.66 \mathrm{~b}$ & 0.50 & 0 & $\ldots$ \\
\hline T3, 0.37 & 34-94 & 56 & $16.6 \mathrm{~b}$ & $0.40 \mathrm{~b}$ & $8.3 \mathrm{~b}$ & $14.55 \mathrm{~b}$ & 2.41 & 50 & 10 \\
\hline $\mathrm{T} 2,0.12$ & $55-125$ & 90 & $5.5 \mathrm{~b}$ & $0.07 \mathrm{~b}$ & $0 \mathrm{~b}$ & $8.77 \mathrm{~b}$ & 1.25 & 0 & $\ldots$ \\
\hline $\mathrm{T} 1,0.04$ & $43-118$ & 81 & $5.5 \mathrm{~b}$ & $0.12 \mathrm{~b}$ & $2.7 \mathrm{~b}$ & $10.21 \mathrm{~b}$ & 2.25 & 50 & 17 \\
\hline
\end{tabular}

u Trees were surveyed each week for symptom development during a 30-month period (November 2000 to July 2003). All disease parameters, except mean mortality time (MM) and weeks to observation of first symptoms (First symptoms) were recorded or calculated at the end of the observation period. Values in columns followed by the same letter are not significantly different at $P=0.05$ according to Fisher's protected least significant difference test.

$\checkmark$ Values of disease parameters as calculated only for diseased trees.

${ }^{\mathrm{w}}$ Treat $=$ treatment; ID expressed as microsclerotia per gram of soil (ppg).

${ }^{x}$ MS = mean severity.

${ }^{y}$ AUDPCP $=$ area under the disease progress severity curve.

${ }^{\mathrm{z}} \mathrm{MM}=$ mean time from symptom onset to plant death. 
regression equation, $y=0.471 x+1.2, r^{2}=$ $0.8693, P$ of the regression $=0.0067$, and $P$ of the constant $=0.0001$. No pattern in the residual distribution was observed. The regressions of untransformed data and the multiple infection transformation also accounted for the relationship in a highly significant manner, but were rejected because the $P$ values for the constants were not statistically significant.

Soil and air temperature, and seasonal increments of disease incidence. The main DI increments during the first year of the experiment occurred in the summer, when the mean air and soil temperature were 26.3 and $23.5^{\circ} \mathrm{C}$, respectively (Figs. 1 and 4). In the second year after planting (2002), however, the largest DI increments were recorded in spring, with 19 new wilted trees, and also in autumn, with 8 new diseased trees. The mean air and soil temperature were 15.9 and $15.5^{\circ} \mathrm{C}$ in the spring and 17.8 and $18.6^{\circ} \mathrm{C}$ in the autumn. In the final year of the study (2003), the DI increment in spring decreased to five new diseased trees. Winter was the season with the smallest number of new symptomatic plants. Plant death occurred mainly in fall 2001 (8 plants) and summer 2002 (13 plants) (Fig. 3). The experiment was finished after summer 2003 because the excessive plant growth called for pruning.

\section{DISCUSSION}

Results of this study provide the first reliable evidence for the relationship between $V$. dahliae levels in soil and progress of VWO. The microplot experimental system used mimicked normal field conditions, allowing major variables influencing the relationship between ID and onset of final values of VWO to be controlled and monitored. These included soil type, irrigation, air and soil temperature, and the amount of inoculum and its distribution. Artificially produced microsclerotia had been tested previously for germinability and infection capability on cotton (20). We found inocula produced on MSPAcellophane plates to also effectively infect olive trees. Periodic assessment of ID in microplots revealed that microsclerotia remained viable in infested soil. Although the accuracy with which the pathogen soil population was detected in different treatments and at different times was not very high, it was acceptable for available methodologies for detecting $V$. dahliae in soil; in fact, the accuracy of wet sieving depends on the particular soil type, among

Table 3. Linear regression analysis of the incidence (\%) of plants with foliar symptoms and severity of symptoms of Verticillium wilt over time in the susceptible olive cv. Picual infested with different inoculum densities (IDs) of Verticillium dahliae ${ }^{\mathrm{y}}$

\begin{tabular}{|c|c|c|}
\hline Disease parameter, treatment, ID $(\mathrm{ppg})^{\mathrm{z}}$ & Regression equation & $r^{2}$ \\
\hline \multicolumn{3}{|l|}{ Incidence } \\
\hline T6, 10.00 & $y=0.08391 x+11.99$ & 0.9275 \\
\hline $\mathrm{T} 5,3.33$ & $y=0.06511 x+8.97$ & 0.8968 \\
\hline $\mathrm{T} 4,1.11$ & $y=0.01905 x-0.77$ & 0.7826 \\
\hline T3, 0.37 & $y=0.01712 x+6.53$ & 0.8478 \\
\hline $\mathrm{T} 2,0.12$ & $y=0.00630 x+0.17$ & 0.7042 \\
\hline $\mathrm{T} 1,0.04$ & $y=0.00591 x+0.71$ & 0.6572 \\
\hline $\mathrm{T} 0,0.00$ & $y=0$ & $\ldots$ \\
\hline \multicolumn{3}{|l|}{ Symptom severity } \\
\hline Т6, 10.00 & $y=0.00265 x+0.25$ & 0.9104 \\
\hline $\mathrm{T} 5,3.33$ & $y=0.00270 x+0.06$ & 0.9390 \\
\hline $\mathrm{T} 4,1.11$ & $y=0.00012 x-0.00556$ & 0.7320 \\
\hline $\mathrm{T} 3,0.37$ & $y=0.000592 x+0.065$ & 0.8838 \\
\hline $\mathrm{T} 2,0.12$ & $y=0.000097 x+0.00474$ & 0.7053 \\
\hline $\mathrm{T} 1,0.04$ & $y=0.000159 x+0.5798$ & 0.5798 \\
\hline $\mathrm{T} 0,0.00$ & $y=0$ & $\ldots$ \\
\hline
\end{tabular}

y $y=$ Disease incidence or symptom severity and $x=$ time; $r^{2}=$ coefficient of determination for each regression line. Regression analyses were performed on untransformed data. In all cases, the error degree of freedom was 58 , and the probability value for statistic $F$ was $P=0.0000$.

${ }^{\mathrm{z}}$ ID expressed as microsclerotia per gram of soil (ppg).

Table 4. Comparison of the slopes of the regression lines of the incidence (\%) of plants with foliar symptoms of Verticillium wilt over time with different inoculum density treatments of Verticillium dahliae

\begin{tabular}{lccc}
\hline & \multicolumn{3}{c}{$\boldsymbol{P}^{\mathbf{y}}$} \\
\cline { 2 - 4 } Treatment versus treatment $^{\mathbf{z}}$ & Slope & Intercept & Equality of variance \\
\hline T6 (10.00 ppg) vs. T5 (3.33 ppg) & 0.0000 & 0.0000 & 0.3249 \\
T5 (3.33 ppg) vs. T3 (0.37 ppg) & 0.0000 & 0.0000 & 0.0000 \\
T4 (1.11 ppg) vs. T3 (0.37 ppg) & 0.2384 & 0.0000 & 0.0073 \\
T4 (1.11 ppg) vs. T2 (0.12 ppg) & 0.0000 & 0.0000 & 0.0000 \\
T4 (1.11 ppg) vs. T1 (0.04 ppg) & 0.0000 & 0.0538 & 0.0000 \\
T2 (0.12 ppg) vs. T1 (0.04 ppg) & 0.0000 & 0.0007 & 0.0000 \\
\hline
\end{tabular}

y $P=$ probability value for statistic $F$.

${ }^{\mathrm{z}}$ Inoculum density expressed as microsclerotia per gram of soil (ppg). other factors $(21,26,27)$. Failure to detect $100 \%$ of the initial inoculum probably resulted from the drainage of microsclerotia by irrigation water, reduction of germinability or death of microsclerotia, or variability or inaccuracy in the measurement method (26). In the last case, the increased amount of microsclerotia detected with treatment T6 probably was a result of secondary inoculum produced from microsclerotia or fungal colonies in the rhizosphere.

Disease symptoms in trees growing in the microplots were similar to those described for young olive trees in soil naturally infested by the pathogen $(6,17)$ or in artificial inoculations under controlled conditions (18). Symptoms first appeared at the end of July of the first year after establishment of the plots, 30 weeks after trees were transplanted to the infested microplots. This was unusual because, in Andalucía, the disease symptoms of wilt and dieback occur mainly in late winter, and defoliation during spring or autumn $(6,17)$. The period over which DI increased in the following seasons and years, especially during the second year after planting (2002), coincided with the typical epidemic development. This suggests that infections presumably occurred later during the first year (at the end of spring or in summer) and likely were due to the time required for the inoculum to become established, for infection to occur, and for the plants to react to infection.

The polyetic character of the epidemic caused by $V$. dahliae probably influenced root infections during the second and third years. As a result, the time duration from plot establishment to when symptoms develop are only tentative because the trees that developed symptoms during a particular season might have been infected the previous season or year and, in some cases, consecutive infection may have been required. However, the incubation periods for trees growing in the microplots infested with 10 and 3.33 ppg were not statistically different. The other treatments were not included in this statistical analysis because of the small number of affected plants. Although too few plants were affected in the lowest ID treatments for reliable comparison, mean mortality time values were seemingly unrelated to the ID in the soil. The reduced increase in DI during the third year after planting (2003) can be ascribed to limitations of the microplot system. Presumably, by this time, roots developed into uninfested soil below the inoculum layer.

One of the main observations of this work is that it confirms the high susceptibility of olive trees to the defoliating pathotype of $V$. dahliae, even when inoculum is present at very low levels in soil. The results clearly show that ID levels above 3 ppg of this pathotype in soil can cause disease in more than $50 \%$ of plants 
and result in more than $40 \%$ plant death and, in as little as 2.5 years in the susceptible cv. Picual, that can result in significant disease. Moreover, susceptibility in the field may be higher because olive tree root systems grow into large volumes of soil during their long lives. This may strongly restrict the establishment of susceptible olive cultivars in zones where highly virulent defoliating pathotypes of $V$. dahliae occur, particularly in areas previously cultivated with susceptible hosts of the pathogen, such as cotton and vegetables $(3,17)$. By way of example, Bejarano-Alcázar et al. (4) found that the mean $V$. dahliae IDs in soil in cotton fields affected by Verticillium wilt in the upper, central, and lower areas of the Guadalquivir Valley (Southern Spain) were $3.4,6.4$, and $37.1 \mathrm{ppg}$, respectively, with an overall mean of $14.4 \mathrm{ppg}$ and a range of 2 to $132 \mathrm{ppg}$. Similarly, ID values ranging from 100 to $200 \mathrm{ppg}$ have been reported for cotton-growing areas in California (25).

The progression of DI and symptom severity over time was characterized in the present study by using a simple straight linear regression of untransformed data. A comparison of regression coefficients revealed that the rate of increase in DI and severity over time differed among ID treatments. Final values of all diseaserelated parameters did not differ between the two highest or the four lowest ID treatments. The highest ID (10 ppg in treatment T6) resulted in a continuous increase in DI throughout the study period; whereas, with T5 (3.33 ppg), there were long periods over which no DI increase was recorded. Because the maximum final DI was $64 \%$ with T6, we can conclude that more than $10 \mathrm{ppg}$ in soil will be required for DI to reach $100 \%$ over a period of 30 months. A similar threshold level was reported previously in cotton by BejaranoAlcázar et al. (4) for the Guadalquivir Valley; they found the ID of a defoliating pathotype of $V$. dahliae required to cause $100 \%$ DI in the highly susceptible cv. Coker-310 to range from 6 to $10 \mathrm{ppg}$.

The relationship between the amount of $V$. dahliae in soil and wilt disease progression has been studied in various herbaceous hosts of this pathogen. Some studies have revealed positive relationships (10,21-23,30); in others, the results were variably influenced by diverse factors including soil type, cultivar, and pathogen race or pathotype $(1,4,12,13,16)$. The relationship between the ID of $V$. dahliae in soil and the final wilt disease incidence has not been well studied in woody hosts. Orchards are established for a long period of time and the tree, pathogen, and environment are continuously interacting. Thus, the amount of inoculum available for infection in a given year, which will play an active role in the annual epidemic, is very difficult to assess. Moreover, the incubation period may be longer than a single growing season, and the number of infections needed to cause disease in a tree and the volume of soil occupied by roots are unknown or highly variable. Therefore, it is impossible to establish an annual relationship between ID and final incidence of
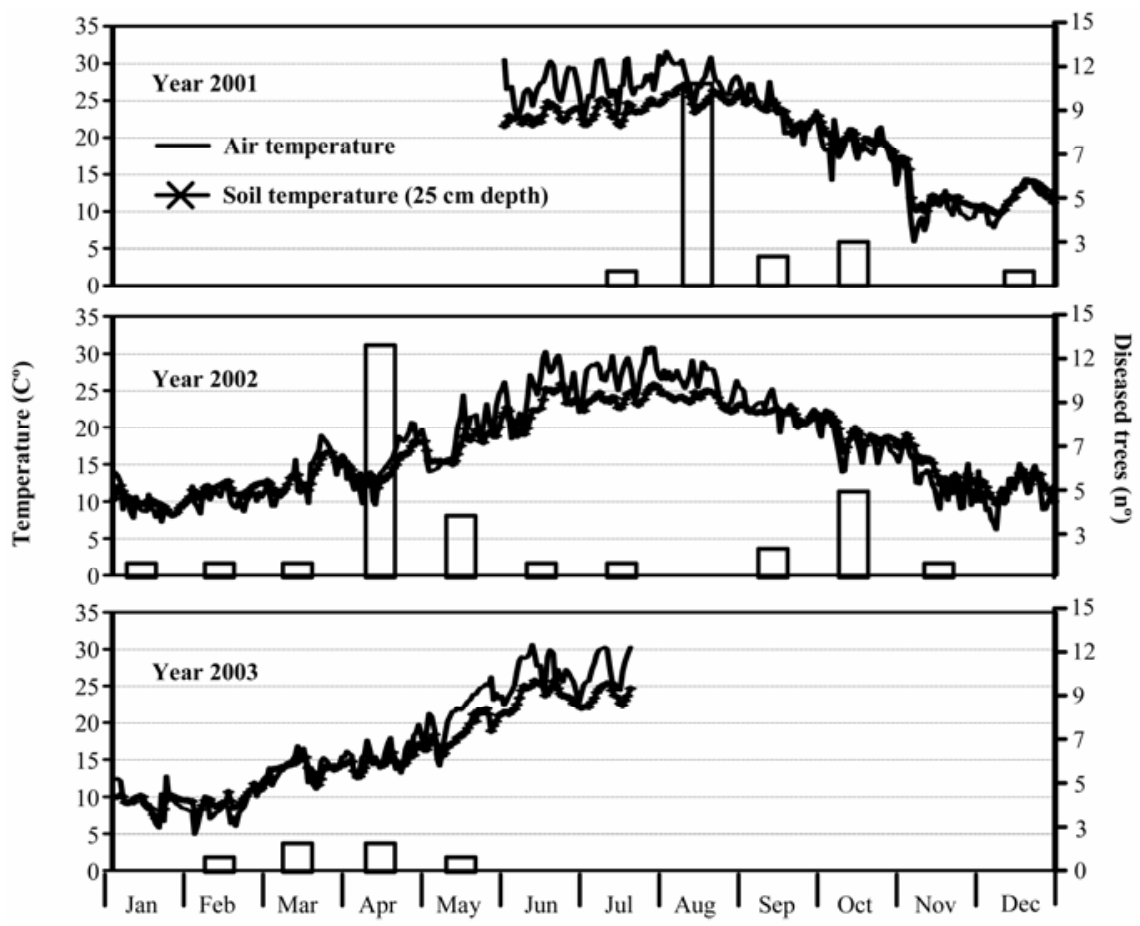

Month of the year

Fig. 4. Average daily air and soil temperatures and monthly number of symptomatic olive trees affected by Verticillium wilt in microplots artificially infested with Verticillium dahliae.

wilt. However, in this work, the results obtained with the three models $\left(r^{2}=0.86\right)$ suggest a positive relationship between the initial ID added to microplots (at planting) and the final values of DI after a long time.

\section{ACKNOWLEDGMENTS}

Research was supported by the European Commission (project reference number QLRT-19991523).

\section{LITERATURE CITED}

1. Ashworth, L. J., Jr., McCutcheon, O. D., and George, A. G. 1972. Verticillium albo-atrum: the quantitative relationship between inoculum density and infection of cotton. Phytopathology 62:901-903.

2. Baker, R. 1971. Analyses involving inoculum density of soil-borne plant pathogens in epidemiology. Phytopathology 61:1280-1292.

3. Bejarano-Alcázar, J., Blanco-López, M. A., Melero-Vara, J. M., and Jiménez-Díaz, R. M. 1996. Etiology, importance and distribution of Verticillium wilt of cotton in southern Spain. Plant Dis. 80:1233-1238.

4. Bejarano-Alcázar, J., Melero-Vara, J. M., BlancoLópez, M. A., and Jiménez-Díaz, R. M. 1995. Influence of inoculum density of defoliating and non-defoliating pathotypes of Verticillium dahliae on epidemics of Verticillium wilt of cotton in southern Spain. Phytopathology 85:1474-1481.

5. Blanco-López, M. A., Bejarano-Alcázar, J., Melero-Vara, J. M., and Jiménez-Díaz, R. M. 1989. Current status of Verticillium wilt of cotton in southern Spain. Pathogen variation and population in soil. Pages 123-132 in: Vascular Wilt Diseases of Plants. E. C. Tjamos and C. H Beckman, eds. NATO ASI Series H: Cell Biology, vol. 28. Springer-Verlag, New York.

6. Blanco-López, M. A., Jiménez-Díaz, R. M., and Caballero, J. M. 1984. Symptomatology, incidence and distribution of Verticillium wilt of olive trees in Andalucía. Phytopathol. Mediterr. 23:1-8.

7. Butterfield, E. J., and DeVay, J. E. 1977. Reassessment of soil assays for Verticillium dahliae. Phytopathology 67:1073-1078.

8. Campbell, C. L., and Madden, L. V. 1990. Introduction to Plant Disease Epidemiology, John Wiley \& Sons, New York.

9. Draper, N. R., and Smith, H. 1981. Applied Regression Analysis, 2nd ed. John Wiley \& Sons, Inc., New York.

10. Francl, L. J., Rowe, R. C., Riedel, R. M., and Madden, L. V. 1988. Effects of three soil types on potato early dying disease and associated yield reduction. Phytopathology 78:159-166.

11. Gregory, P. H. 1948. The multiple infection transformation. Ann. Appl. Biol. 35:412-417.

12. Grogan, R. G., Ioannou, N., Schneider, R. W., Sall, M. A., and Kimble, K. A. 1979. Verticillium Wilt on resistant tomato cultivars in California: virulence of isolates from plants and soils and relationship of inoculum density to disease incidence. Phytopathology 69:11761180.

13. Harris, D. C., and Yang, J. R. 1996. The relationship between the amount of Verticillium dahliae in soil and the incidence of strawberry wilt as a basis for disease risk prediction. Plant Pathol. 45:106-114.

14. Hiemstra, J., and Harris, D. 1998. Compendium of Verticillium Wilt in Tree Species. Ponsen \& Looijen, Wageningen, The Netherlands.

15. Huisman, O. C., and Ashworth, L. J. 1974. Quantitative assessment of Verticillium albo-atrum in field soils: procedural and substrate improvements. Phytopathology 64:1043-1044.

16. Khan, A., Atibalentja, N., and Eastburn, D. M 2000. Influence of inoculum density of Verticillium dahliae on root discoloration of horseradish. Plant Dis. 84:309-315. 
17. López-Escudero, F. J., and Blanco-López, M. A. 2001. Effect of a single or double soil solarization to control Verticillium wilt in established olive orchards in Spain. Plant Dis. 85:489-496.

18. López-Escudero, F. J., del Río, C., Caballero, J. M., and Blanco-López, M. A. 2004. Evaluation of olive cultivars for resistance to Verticillium dahliae. Eur. J. Plant Pathol. 110:79-85.

19. Martos-Moreno, C., and Blanco-López, M. A. 2001. Epidemiological behavior of olive cultivars in orchards infested with mixtures of defoliating and non-defoliating isolates of Verticillium dahliae. Page 67 in: Proc. 8th Int. Verticillium Symp., Córdoba, Spain. Universidad de Córdoba and Consejo Superior de Investigaciones Científicas, Spain.

20. Mwanza, C. 2002. Control de Verticillium dahliae en el suelo mediante la aplicación de residuos orgánicos. Ph.D. thesis, Universidad de Córdoba, Spain.

21. Nicot, P. C., and Rouse, D. I. 1987. Relationship between soil inoculum density of Verticillium dahliae and systemic colonization of potato stems in commercial fields over time.
Phytopathology 77:1346-1355.

22. Paplomatas, E. J., Bassett, D. M., Broome, J. C., and DeVay, J. E. 1992. Incidence of Verticillium Wilt and yield losses of cotton cultivars (Gossypium hirsutum) based on soil inoculum density of Verticillium dahliae. Phytopathology 82:1417-1420.

23. Pullman, G. S., and DeVay, J. E. 1982. Epidemiology of Verticillium wilt of cotton: a relationship between inoculum density and disease progression. Phytopathology 72:549-554.

24. Rodríguez-Jurado, D., Blanco-López, M. A., Rappoport, H. F., and Jiménez-Díaz, R. M. 1993. Present status of Verticillium wilt of olive in Andalucía (southern Spain). EPPO Bull. 23:513516.

25. Schnathorst, W. C. 1981. Verticillium wilt. Pages 41-44 in: Compendium of Cotton Diseases. G. M. Watkins, ed. American Phytopathological Society, St. Paul, MN.

26. Termorshuizen A. J. 2000. Interlaboratory comparison of methods to quantify microsclerotia of Verticillium dahliae in soil. Pages 122124 in: Advances in Verticillium. Research and
Disease Management. E. C. Tjamos, R. C. Rowe, J. B. Heale, and D. R. Fravel, eds. American Phytopathological Society Press, St. Paul, MN.

27. Termorshuizen, A. J., and Mol, L. 1995. Modeling the dynamics of Verticillium dahliae. Pages 265-280 in: Potato Ecology and Modeling of Crops Under Conditions Limiting Growth. A. J. Haverkort and D. K. L. MacKerron, eds. Kluwer Academic Publishers, Dordrecht, The Netherlands.

28. Tjamos, E. C, Biris, D. A and Paplomatas, E. J. 1991. Recovery of olive trees with Verticillium wilt after individual application of soil solarization in established olive orchards. Plant Dis. 75:557-562.

29. Van der Plank, J. E. 1963. Plant Diseases: Epidemics and Control. Academic Press, Inc., New York.

30. Xiao, C. L., and Subbarao, K. V. 1998. Relationships between Verticillium dahliae inoculum density and wilt incidence, severity, and growth of cauliflower. Phytopathology 88: 1108-1115. 